\title{
Headwind, a Scanning Story
}

\section{Chantal Faust \\ * 1980 Melbourne, Australia | London, UK}

Chantal Faust's research activities centre on the apparatus of the scanner as surrogate camera, offering a meditation on the mechanical apparatus and what it gives forth, both practically and metaphorically. The mechanism is considered as a mirror, a glass, a void and a machine where touch is the operative at play. These avenues of analysis allow for a consideration on pleasure and the meaning of loss, love and perfection, death, memory and mourning. Probing the insides of the making process itself, a correlation is made between the act of scanning and the operations of the conscious and unconscious mind. Recent exhibitions include There Is A Hole In The Bagel-Chantal Faust + Ruidi Mu, Gallery TOM, Tokyo (2019); Solitary Pleasures, Freud Museum, London (2018); Natur Blick, Koppel Project Hive, London (2018); and Antipodean Emanations, Monash Gallery of Art, Melbourne (2018). Recent book chapters include "The Masochistic Pulse" in Dark Habits, Cornerhouse Publications and "Thinking Through Outline" in Anchor, Marmalade Publishers of Visual Theory. Faust's monograph, Pleasure Machines: Towards a Philosophy of Scanning forthcoming, Bloomsbury (2021). This work addresses the philosophical and aesthetic implications of the now ubiquitous flatbed scanner and how this imaging machine signifies a shift from normative and ocularcentric histories of lenticular seeing, emphasising processes of visualisation and data recording as close-up, corporeal, and dependent upon intimacy and touch. Chantal Faust is Head of Contemporary Art Practice (CAP) at the Royal College of Art and editor-in-chief editor of Prova.

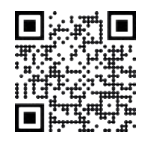

junction ['d子^ykJən]

the contact point between data and definition. 'up the junction':

slang for being pregnant. 

WHEN I AM WALKING 


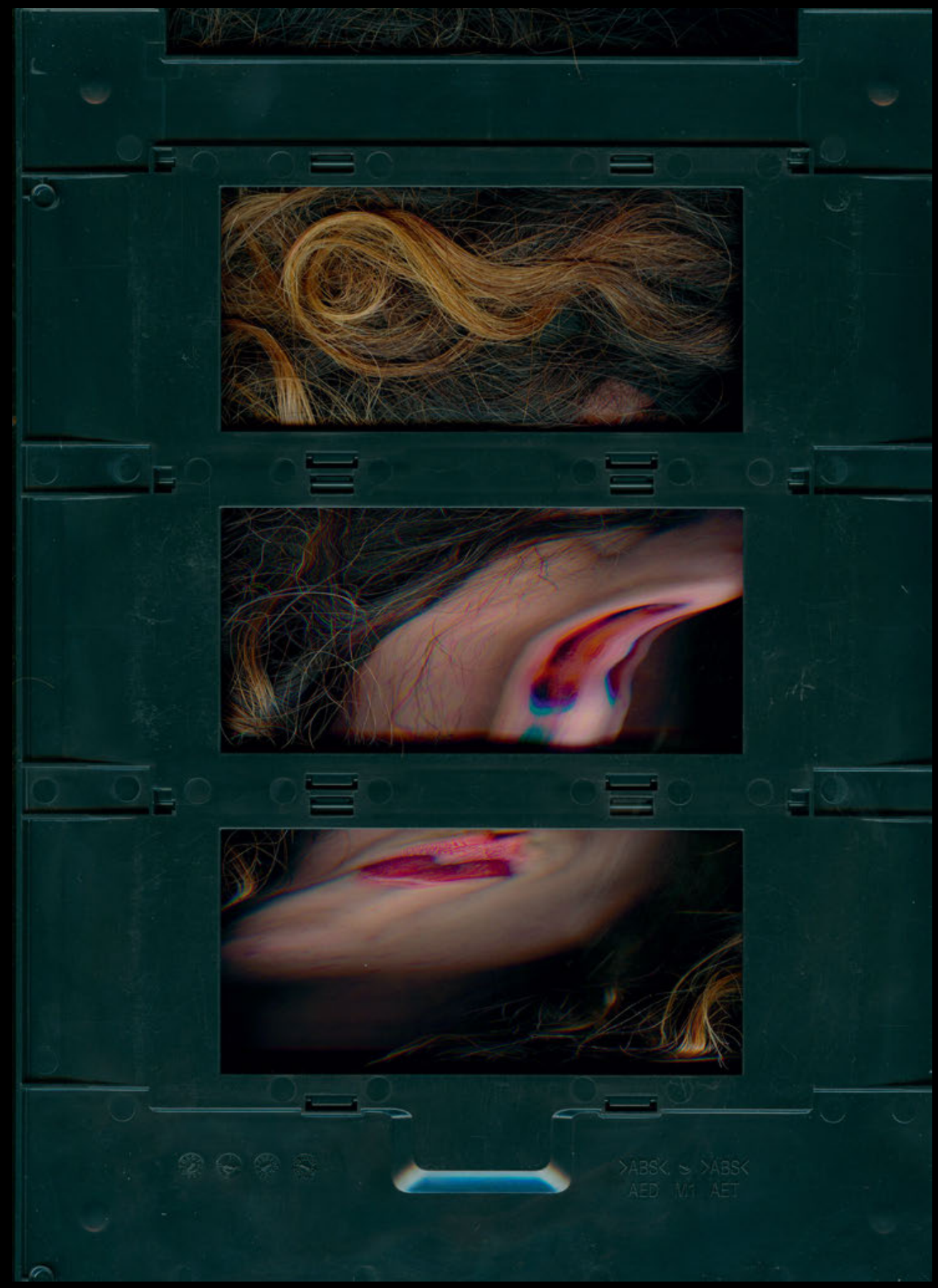




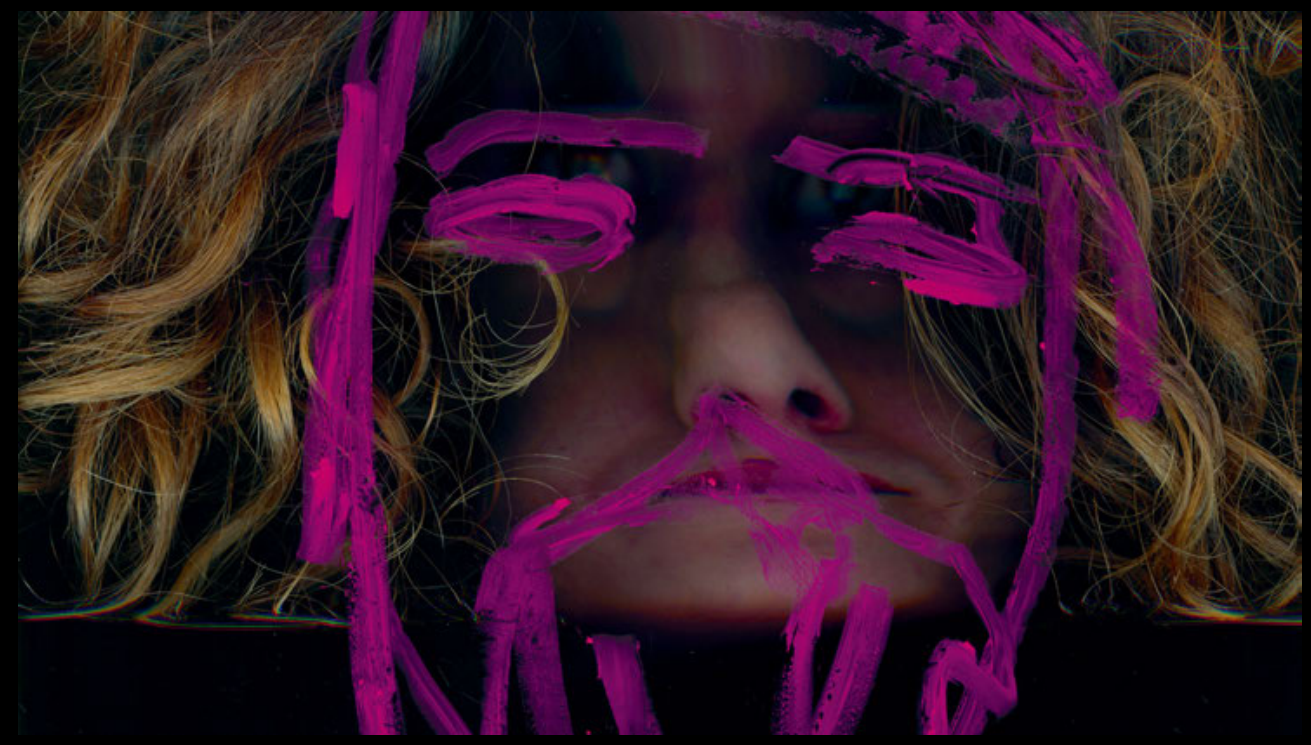




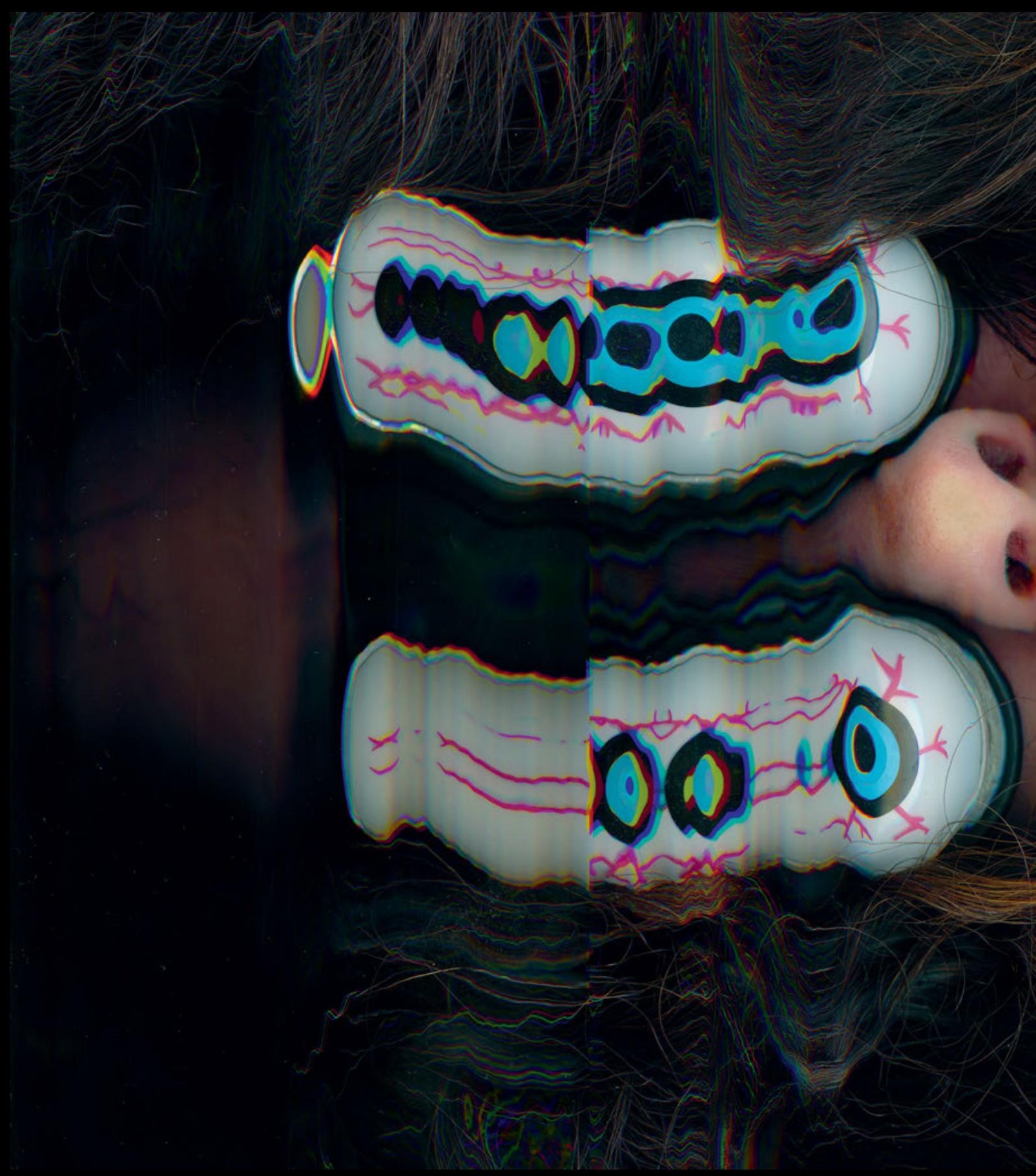




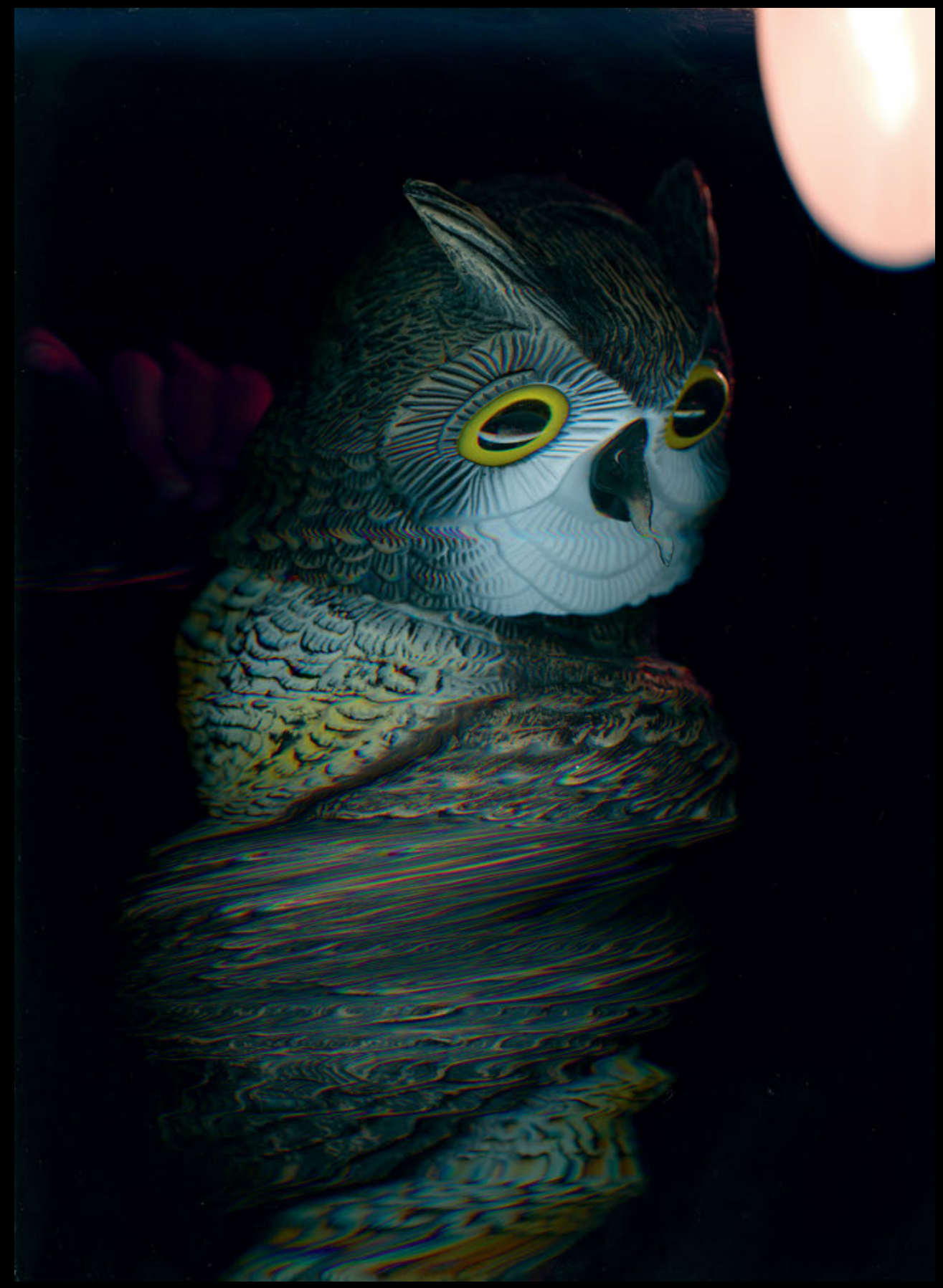




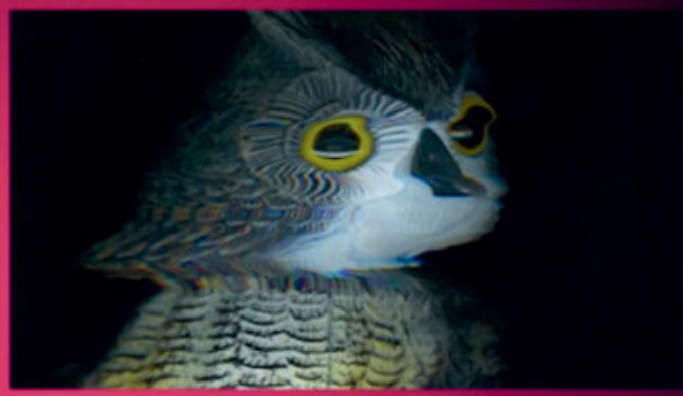




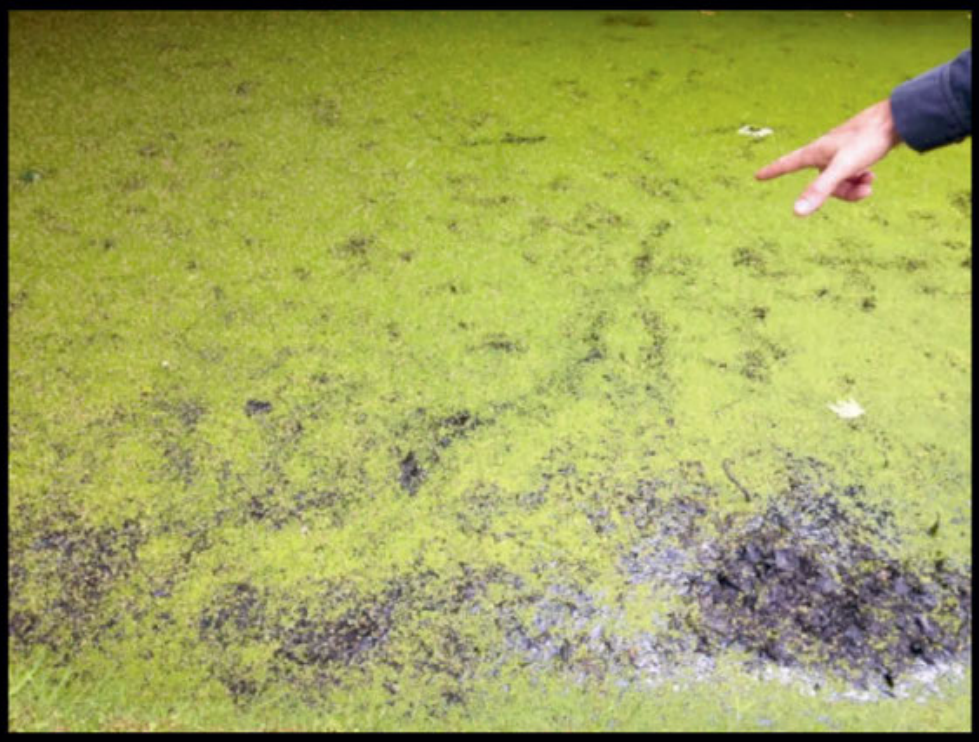




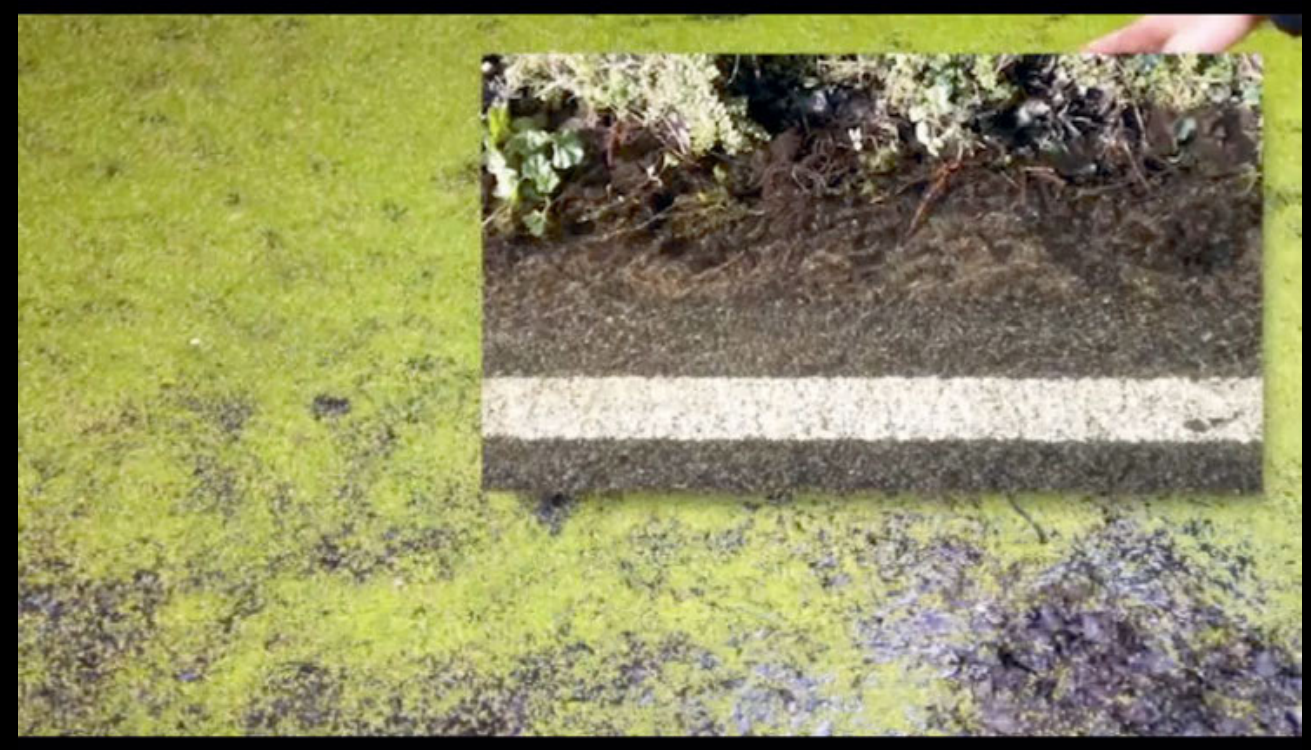




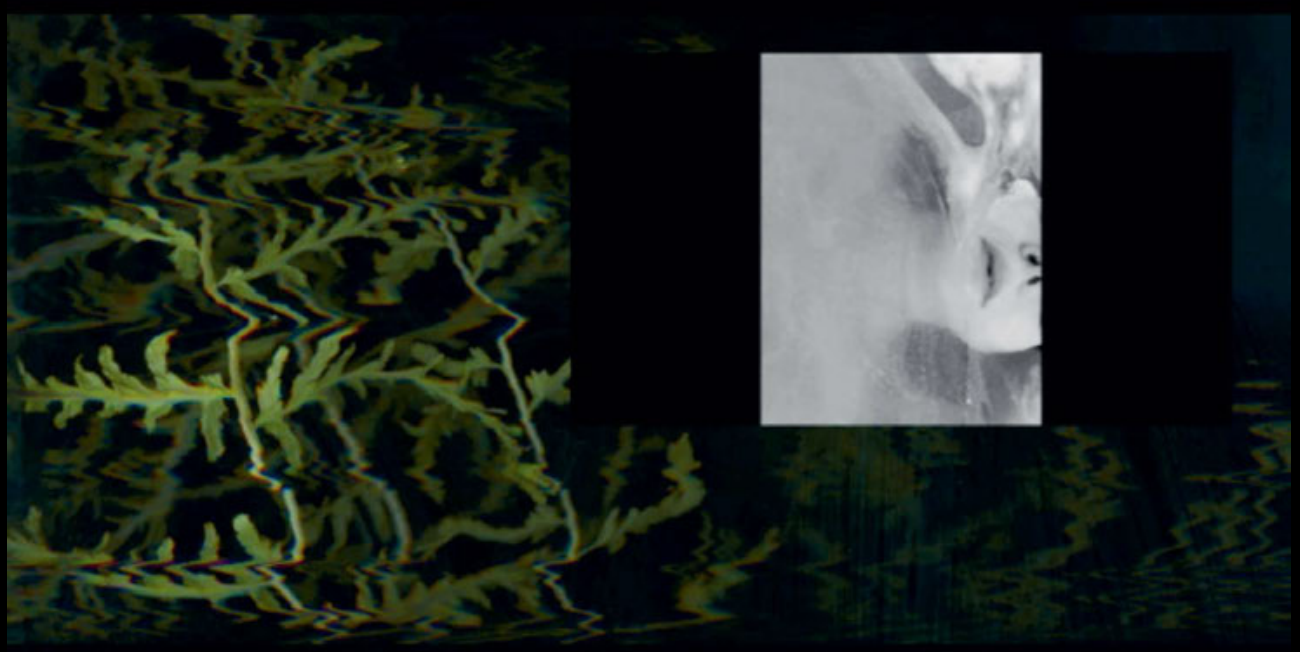




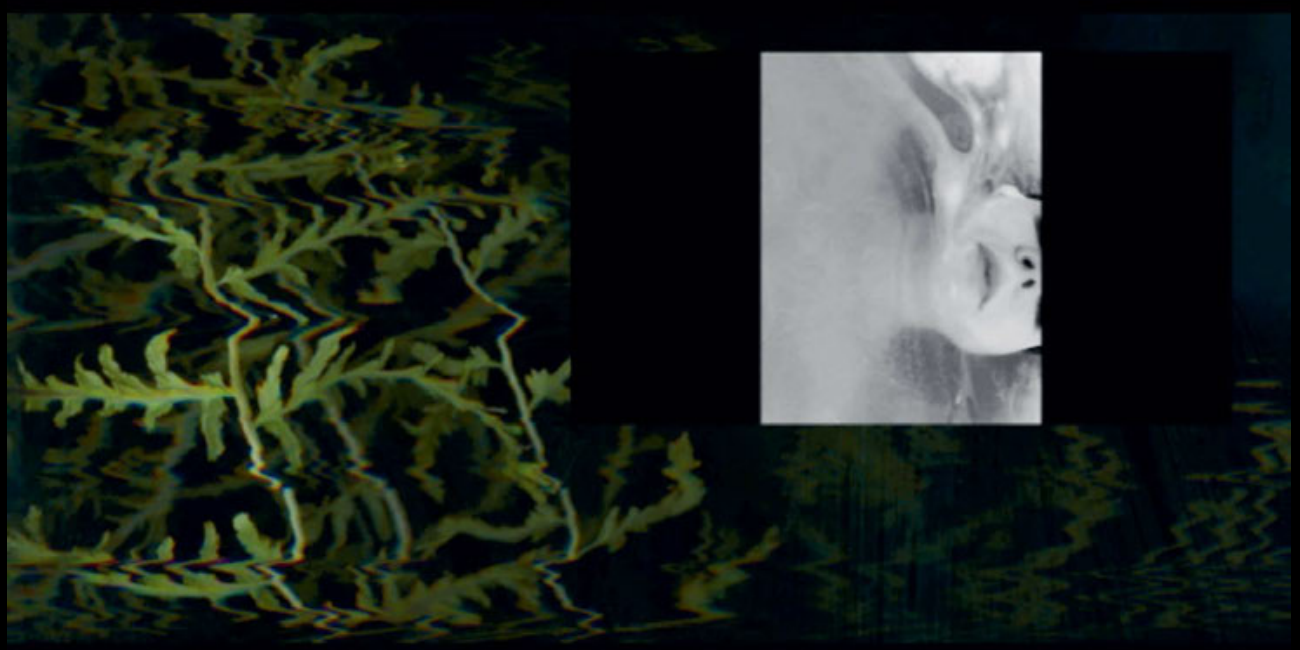

I'm trying. I'm trying to walk more in this city. 
I'm trying. I'm trying to walk 
nore in this city. I'm trying to walk more. 


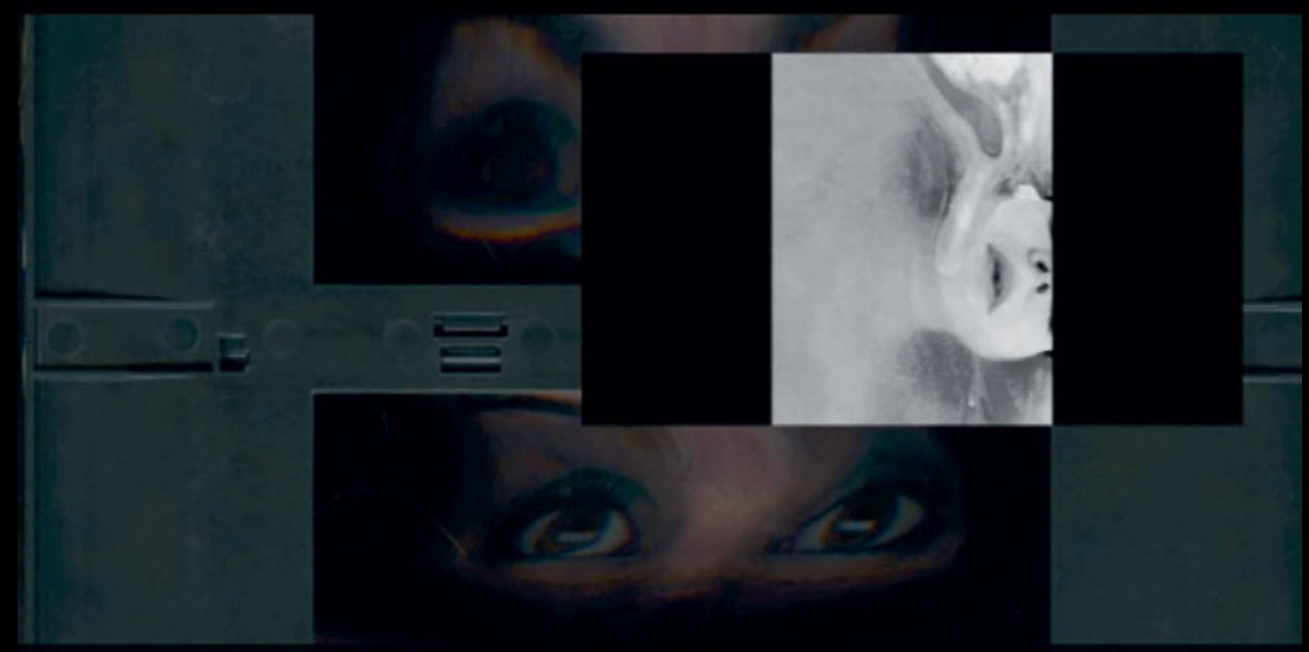

Ieople. And see things. Not going anywhere. I'm trying to walk more in this city. I'r 


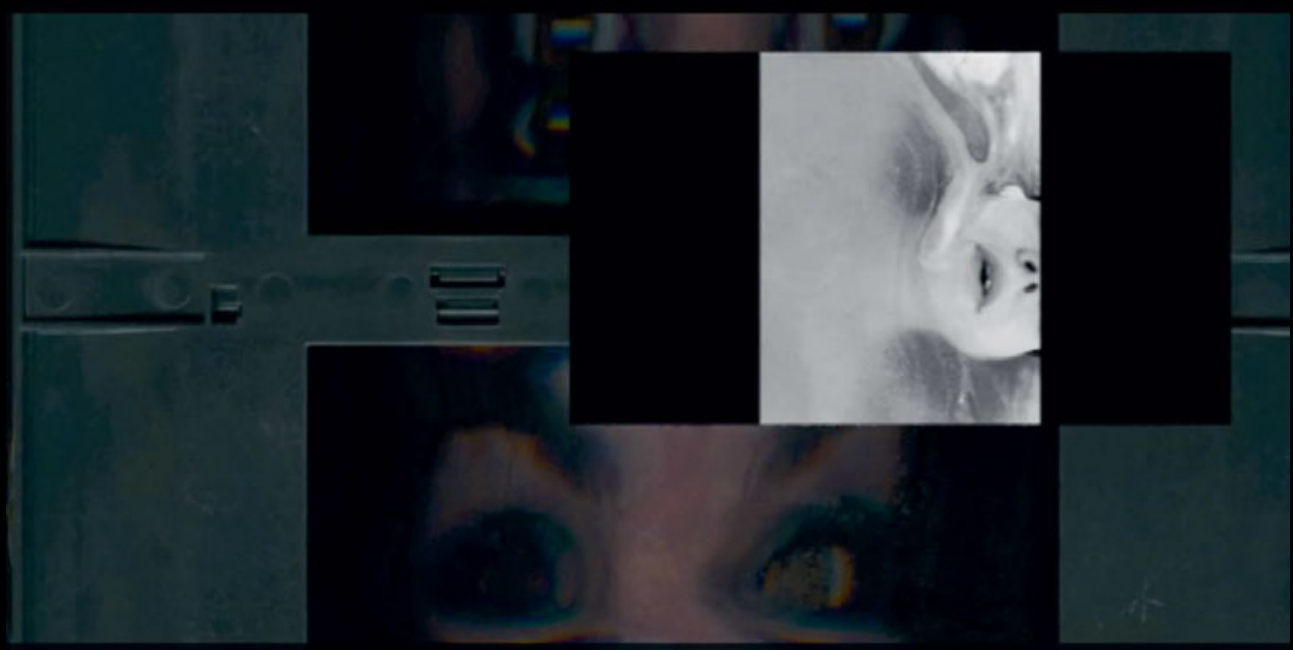

ere. I'm trying to walk more in this city. I'm trying to do different things. I'm tryinc 

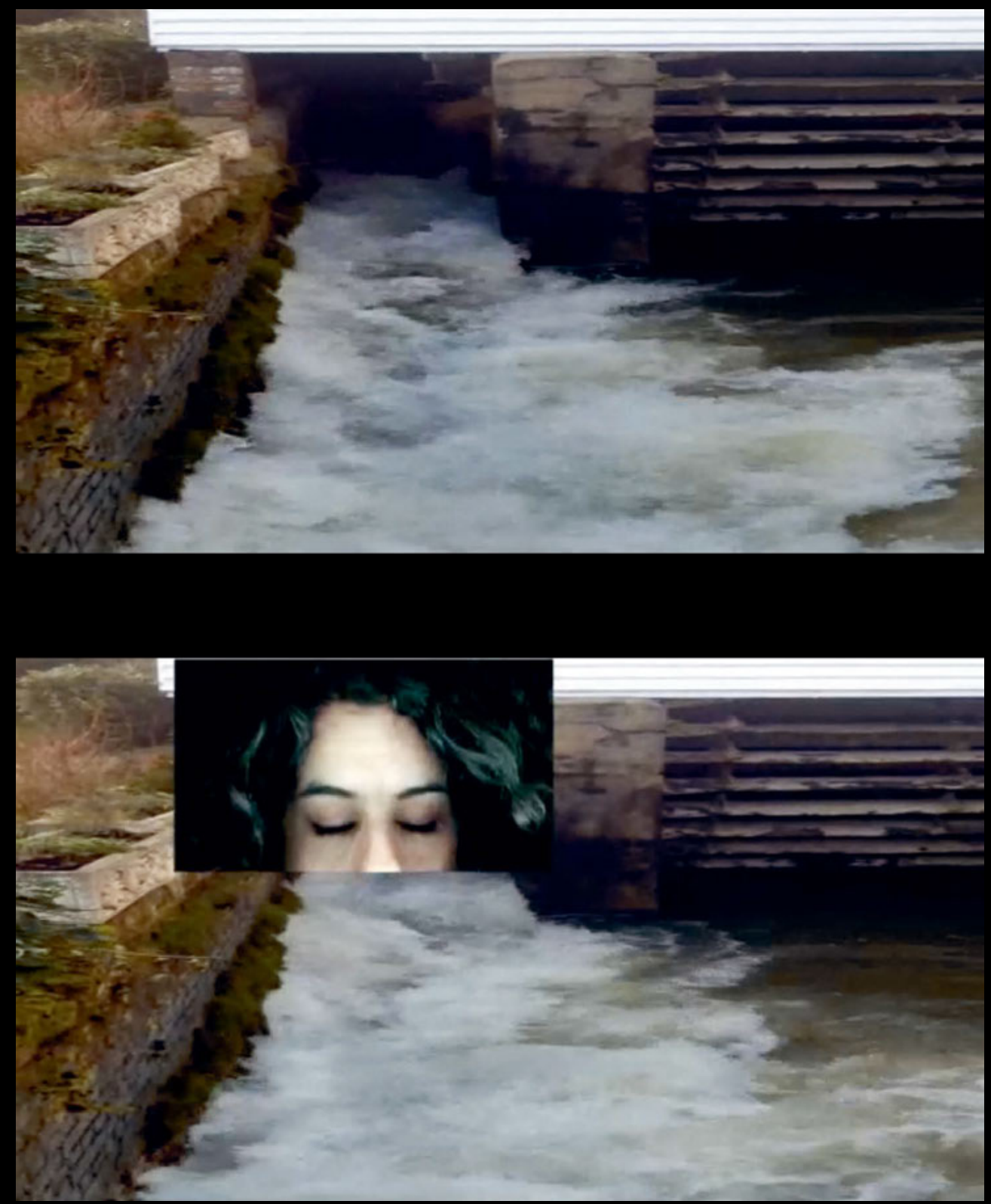

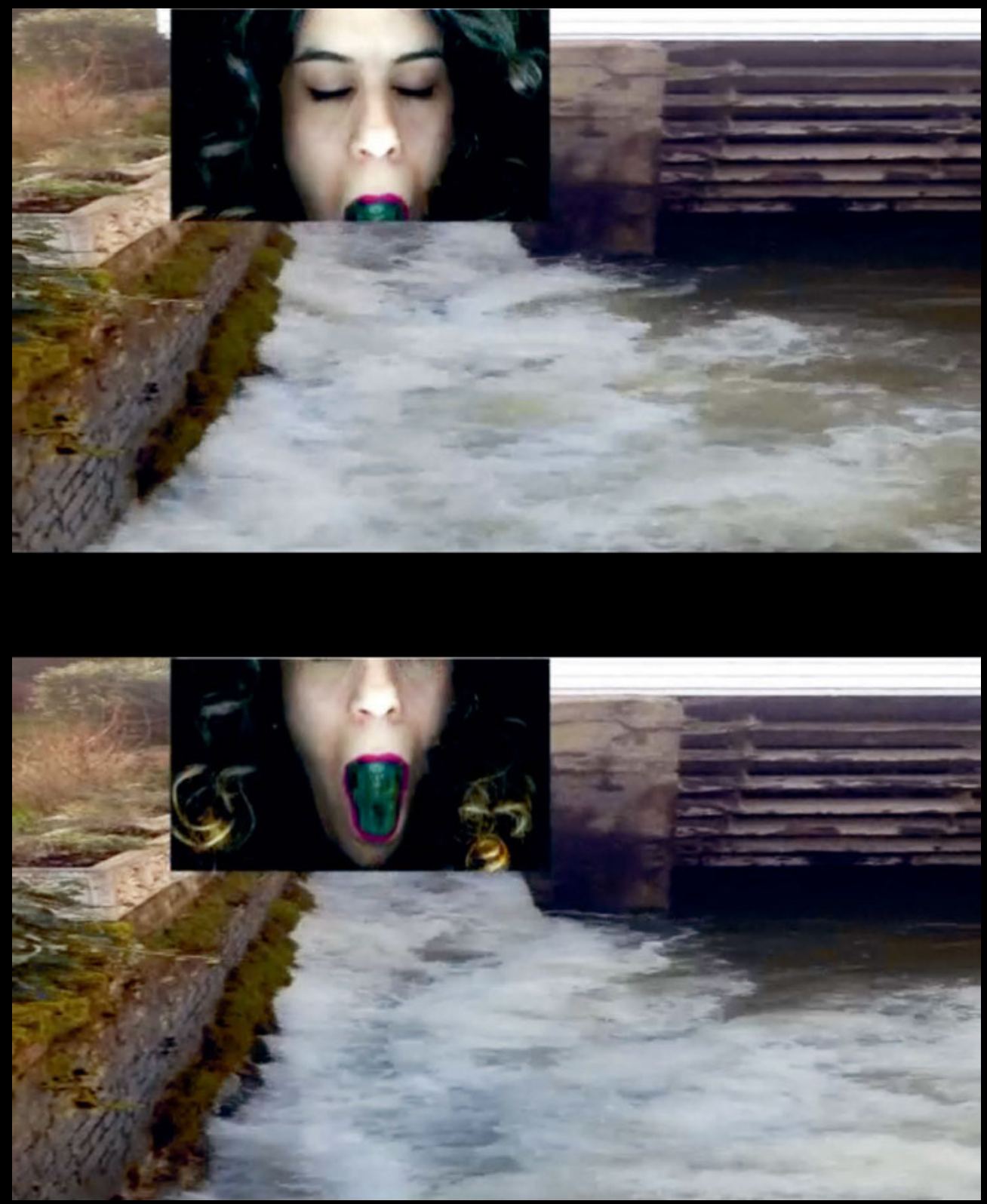


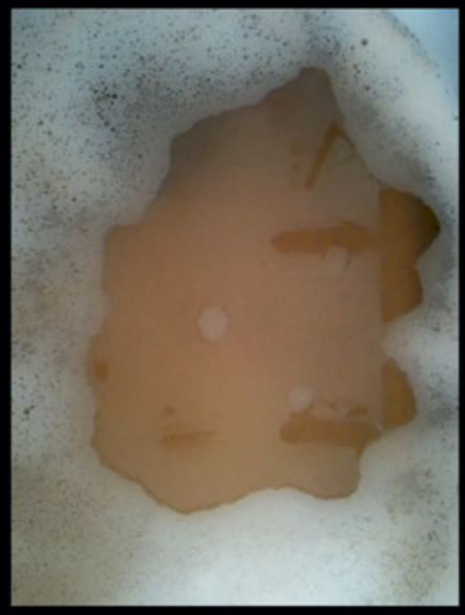


Watching window cleaners from the other side is endlessly appealing.

Shaving the glass to see like a tongue pressed against a face.

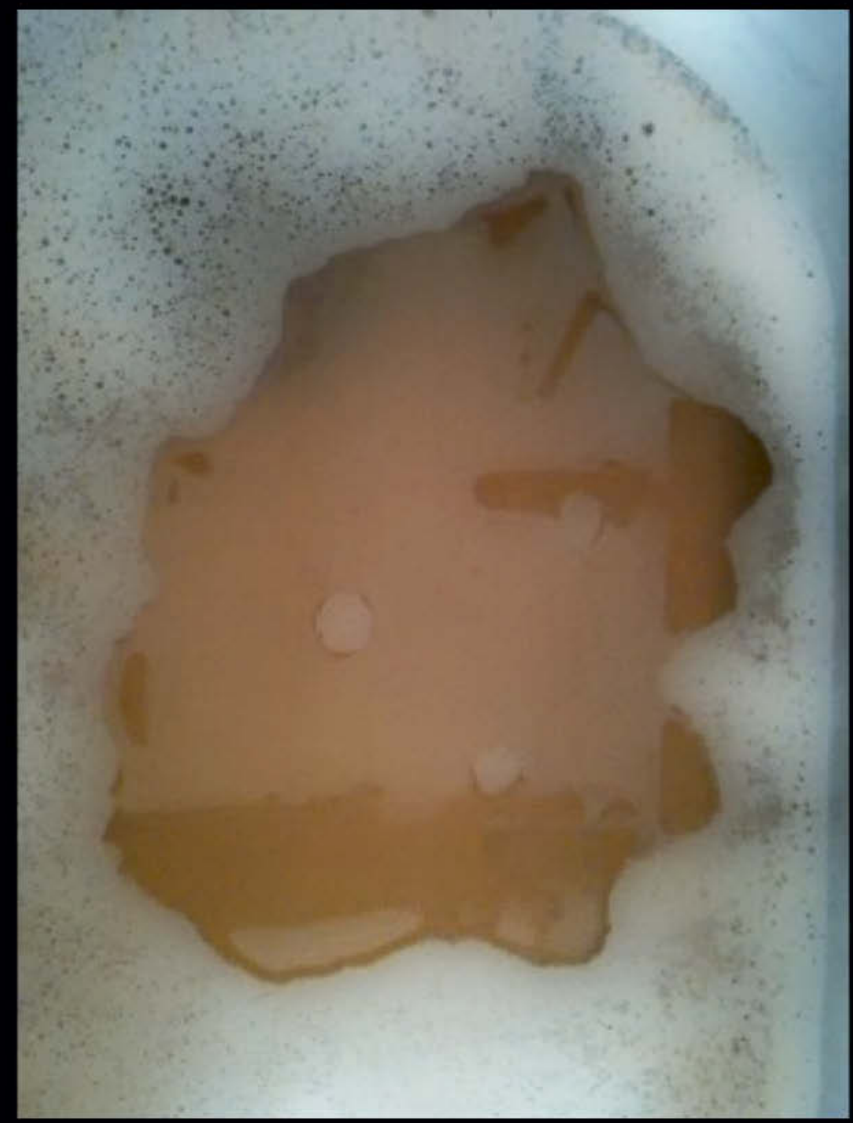



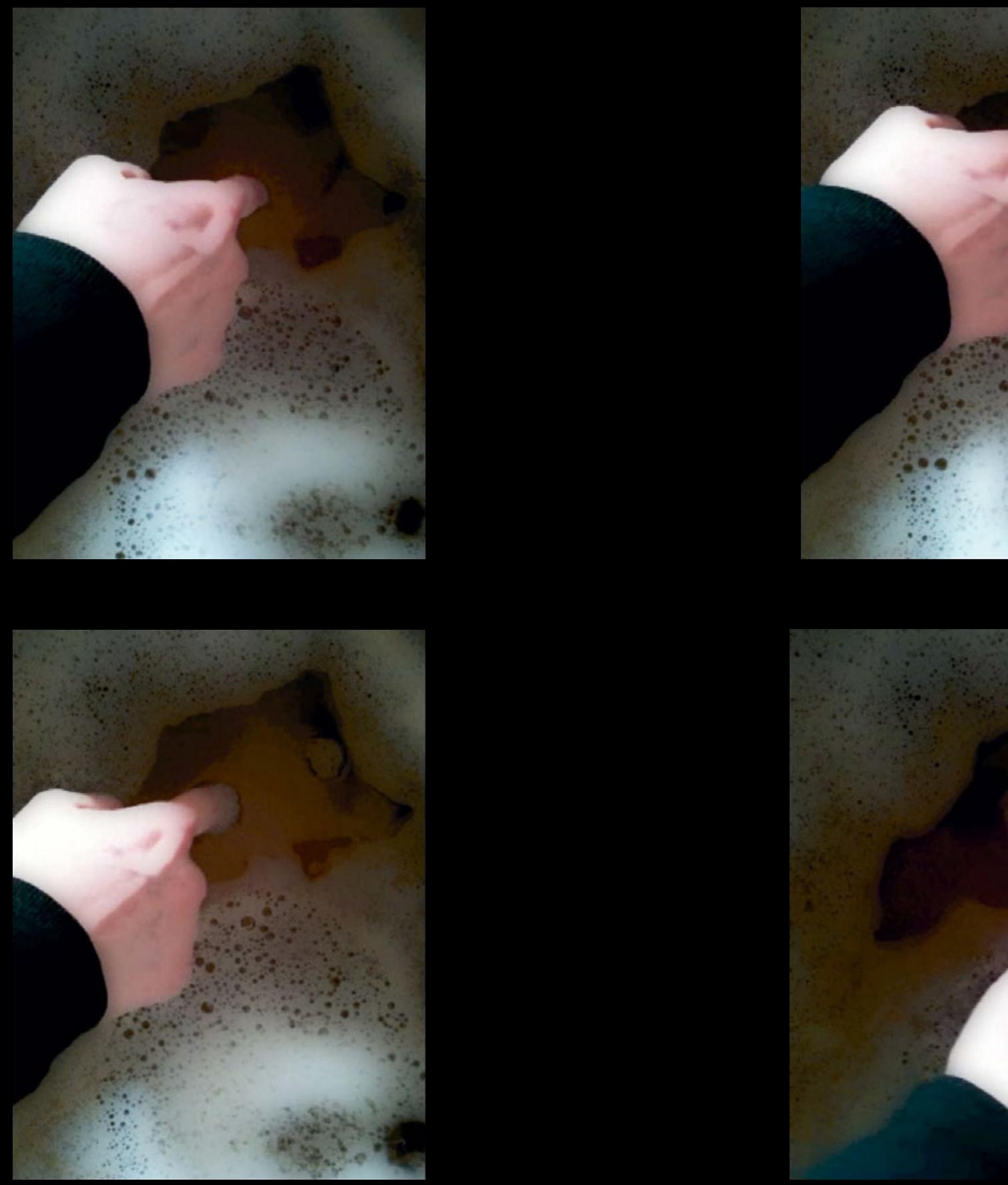


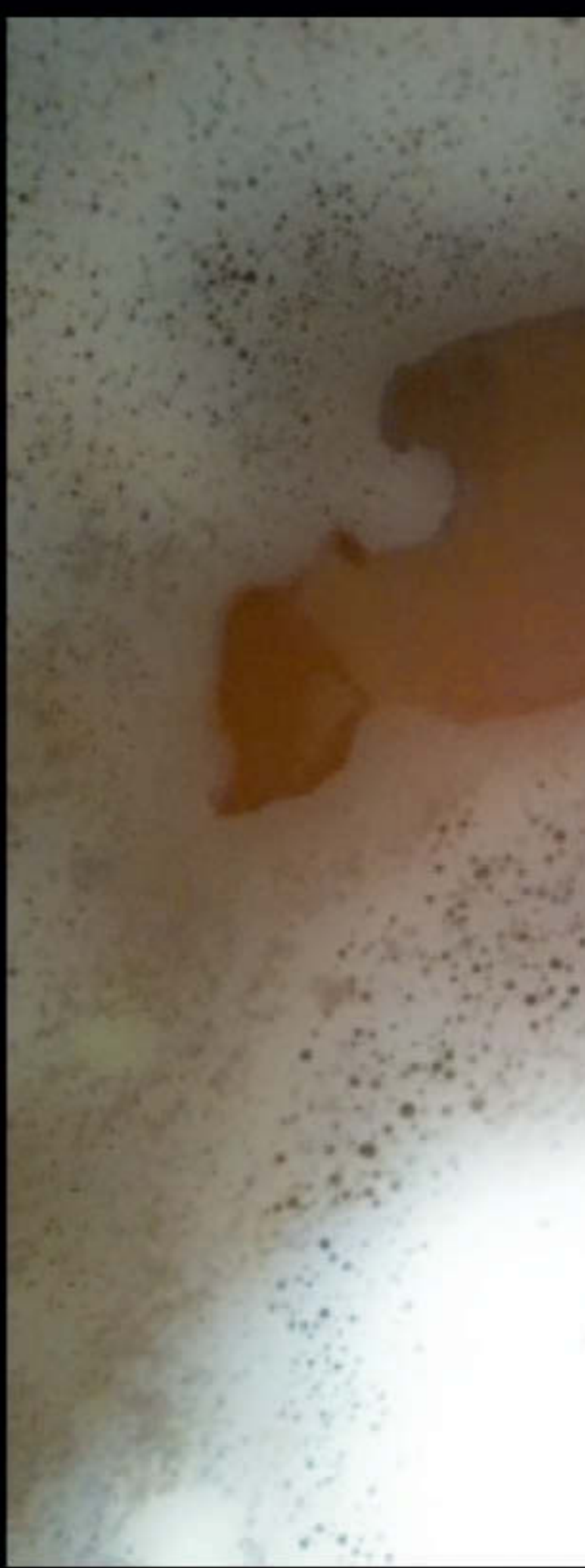


